\title{
Role Of MRI Versus Ultrasound In Assessment Of Placental Abnormalities Regarding Morphology, Location And Implantation.
} Ashraf Talaat(1),Abdallah Abass(2),Amira Hamdy(3)

(1) assistan professor,radiology department, faculty of medicine fayoum university.

(2) lecturer,radiology department,faculty of medicine,fayoum university.

(3) Master degree of radiology department,faculty of Medicine ,Fayoum University. Corresponding author:Abdallah abbas.
E-mail address:abdallah1311@ gmail.com

\section{ABSTRACT \\ KEYWORDS \\ Ultrasound. \\ MR. \\ Previa. \\ Accreta}

In recent years, there has been increased interest in magnetic resonance (MR) imaging for the evaluation of placental abnormalities regarding location and implantation, since it can provide information on depth of invasion and more clearly depict posterior placentas.
3) Results.

4) Discussion.

5) Conclusion.

6) References.

\section{INTRODUCTION}

In recent years, there has been increased interest in magnetic resonance (MR) imaging for the evaluation of placenta accrete (PA), since it can provide information on depth of invasion and more clearly depict posterior placentas. It can be used as complementary imaging modality and problem solving method especially with equivocal ultrasound or Doppler examination and when further characterization is required.

\section{ARTICLE STRUCTURE}

1) Review of literature.

1.1. Anatomical background

1.2. Pathology of the placenta

1.3. Sonography and placental abnormalities

1.4. MR imaging of the placenta

2) Patients and methods.

\section{PATIENTS AND METHODS}

\section{Patients:}

The current study had been approved by Fayoum Univrsity Hospital Ethical 
committee, Fayoum University; all the included fifty cases gave informed consent.

\section{Inclusion criteria:}

1_age: range from 20 to 45 years old.

2_patients with suspected placental abnormalities in morphology ,location and or implantation by ultrasound.

3 _ previous cesarean section.

4_history of curettage or myomectomy.

\section{Exclusion criteria:}

1_ first trimester pregnancy.

2_ patients with fundal placenta.

3_patients with claustrophobia, pacemaker, insulin pump andlor vascular clips.

\section{Methods:}

All of the cases (50/50 cases) were subjected to both Ultrasound (US) and (MRI) of the pelvis prior to elective delivery (P36 weeks gestation).

\subsection{Ultrasound examination}

Scanning was performed using LOGIQ S8, GE (General electric medical system) ultrasound machine where:

(1) Transabdominal approach (gray scale, color (power Doppler and Bflow) for all cases using 3-5 MHz sector transducer.

(2) Transvaginal approach (gray scale and colorlpower Doppler ) using 7-8 MHz endoluminal transducer .

\subsection{Magnetic resonance imaging}

MRI was performed for all cases using (Toshiba Titan 1.5- Tesla)

MRI evaluation of the placenta was done in all cases with placenta previa included in the study to provide more accurate diagnosis of the placental location, type of previa and to check for radiological signs of placental invasion even if preliminary US was negative .

Cases were imaged in the supine position using phased-array pelvic coil.

The maternal pelvis was scanned using the following protocol:

(1) T2-weighted pulse sequencefast spin echo (FSE).

(2) T1-weighted sequence-spin echo (SE).

(3) Balanced fast field echo (BFFE).

(4) T2 Single Shot spin echo (SSh-SE).

For all the aforementioned sequences slice thickness $=5-6 \mathrm{~mm}$ with $1 \mathrm{~mm}$ gap, flip angle $=90 \_$and $\mathrm{FOV}=370-400 \mathrm{~mm}$.

Sequences (1) and (2) were performed with respiratory triggering to control maternal and fetal motion artifacts.

Total scanning time is $32 \mathrm{~min}$.

No intravenous injection of gadolinium was used in all cases. 


\section{Image analysis:}

Ultrasound analysis (transabdominal approach) was performed.

Placenta previa was subdivided according to the position of the placenta relative to the internal cervical os following Elsayes et al. (1) into: (1) low-lying, (2) marginal, (3) complete, (4) central.

Placenta previa findings that were considered suggestive of accreta/percreta on US had been based on Magied, Asmaa M. Abdel, et al.(2018) and included: (1) loss of the retroplacental hypoechoic clear zone, (2) focal bulge with myometrial thinning $(<1 \mathrm{~mm})$, (3) loss of the bladder wall-uterine interface, (4) presence of placental lacunae (vascular spaces), and (5) presence of hypervascularity of the interface between the uterine serosa and the bladder wall on color Doppler imaging.

Regarding MRI; findings of placenta accreta/percreta following Silver, Robert M.,et al. (2015) in addition of being previa included: (1) uterine bulging, (2) heterogeneous signal intensity within the placenta, (3) dark intraplacental bands on T2-WI, (4) focal interruptions in the myometrial wall, (5) tenting of the bladder, (6) direct visualization of the invasion of pelvic structures by placental tissue.

\section{RESULTS}

Table (1): Comparisons of ultrasound findings in different operative findings.

\begin{tabular}{|c|c|c|c|c|c|c|}
\hline \multirow{3}{*}{$\begin{array}{c}\text { Variables } \\
(\mathbf{m m})\end{array}$} & \multicolumn{4}{|c|}{ operative findings } & \multirow{3}{*}{$\begin{array}{c}\text { p-value } \\
\text { (OR) }\end{array}$} & \multirow{3}{*}{ Sig. } \\
\hline & \multicolumn{2}{|c|}{$\begin{array}{c}\text { Negative } \\
(\mathrm{n}=28)\end{array}$} & \multicolumn{2}{|c|}{$\begin{array}{c}\text { Positive } \\
(\mathrm{n}=22)\end{array}$} & & \\
\hline & No. & $\%$ & No. & $\%$ & & \\
\hline \multicolumn{7}{|c|}{ Retro-placental hypoechoic zone } \\
\hline Not clarified & 0 & $0 \%$ & 8 & $36.4 \%$ & \multirow{2}{*}{$\begin{array}{c}0.02 \\
(\mathrm{OR}=3)\end{array}$} & \multirow{2}{*}{$\mathbf{S}$} \\
\hline Clarified & 28 & $100 \%$ & 14 & $63.6 \%$ & & \\
\hline \multicolumn{7}{|c|}{ Prominent Vascular lacunae } \\
\hline Absent & 18 & $64.3 \%$ & 10 & $45.5 \%$ & \multirow{2}{*}{0.3} & \multirow{2}{*}{ NS } \\
\hline Present & 10 & $35.7 \%$ & 12 & $54.5 \%$ & & \\
\hline
\end{tabular}


Table (2): Comparisons of MRI findings in different operative findings.

\begin{tabular}{|c|c|c|c|c|c|c|}
\hline \multirow{3}{*}{$\begin{array}{c}\text { Variables } \\
\quad(\mathbf{m m})\end{array}$} & \multicolumn{4}{|c|}{ operative findings } & \multirow{3}{*}{$\begin{array}{c}\text { p-value } \\
\text { (OR) }\end{array}$} & \multirow{3}{*}{ Sig. } \\
\hline & \multicolumn{2}{|c|}{$\begin{array}{c}\text { Negative } \\
(\mathrm{n}=28)\end{array}$} & \multicolumn{2}{|c|}{$\begin{array}{c}\text { Positive } \\
(\mathrm{n}=22)\end{array}$} & & \\
\hline & No. & $\%$ & No. & $\%$ & & \\
\hline \multicolumn{7}{|c|}{ Homogenicity of the Placenta } \\
\hline Homogenous & 24 & $85.7 \%$ & 6 & $27.3 \%$ & \multirow{2}{*}{$\begin{array}{c}0.005 \\
(\mathrm{OR}=16)\end{array}$} & \multirow{2}{*}{ HS } \\
\hline Heterogeneous & 4 & $14.3 \%$ & 16 & $72.7 \%$ & & \\
\hline \multicolumn{7}{|l|}{ Dark Bands of T2 } \\
\hline Absent & 24 & $85.7 \%$ & 6 & $27.3 \%$ & \multirow{2}{*}{$\begin{array}{c}0.005 \\
(\mathrm{OR}=16)\end{array}$} & \multirow{2}{*}{ HS } \\
\hline Present & 4 & $14.3 \%$ & 16 & $72.7 \%$ & & \\
\hline \multicolumn{7}{|l|}{ Uterine Bulge } \\
\hline Absent & 22 & $78.6 \%$ & 4 & $18.2 \%$ & \multirow{2}{*}{$\begin{array}{c}0.004 \\
(\mathrm{OR}=\mathbf{1 6 . 5})\end{array}$} & \multirow{2}{*}{ HS } \\
\hline Present & 6 & $21.4 \%$ & 18 & $81.8 \%$ & & \\
\hline
\end{tabular}

Table (3): Comparisons of ultrasound and MRI findings in different operative findings.

\begin{tabular}{|c|c|c|c|c|c|c|}
\hline \multirow{3}{*}{$\begin{array}{c}\text { Variables } \\
(\mathbf{m m})\end{array}$} & \multicolumn{4}{|c|}{ operative findings } & \multirow{3}{*}{$\begin{array}{c}p- \\
\text { value }\end{array}$} & \multirow{3}{*}{ Sig. } \\
\hline & \multicolumn{2}{|c|}{$\begin{array}{c}\text { Negative } \\
(n=28)\end{array}$} & \multicolumn{2}{|c|}{$\begin{array}{c}\text { Positive } \\
(\mathrm{n}=22)\end{array}$} & & \\
\hline & No. & $\%$ & No. & $\%$ & & \\
\hline \multicolumn{7}{|l|}{ Final US finding } \\
\hline Negative & 28 & $100 \%$ & 8 & $36.4 \%$ & \multirow{2}{*}{0.001} & \multirow{2}{*}{ HS } \\
\hline Positive & 0 & $0 \%$ & 14 & $63.6 \%$ & & \\
\hline \multicolumn{7}{|l|}{ Final MRI finding } \\
\hline Negative & 24 & $85.7 \%$ & 2 & $9.1 \%$ & \multirow[t]{2}{*}{$<0.001$} & \multirow{2}{*}{ HS } \\
\hline Positive & 4 & $14.3 \%$ & 20 & $90.9 \%$ & & \\
\hline
\end{tabular}


Table (4): Sensitivity and specificity of US and MRI in comparison with final operative findings in diagnosis of placental status.

\begin{tabular}{|c|c|c|c|c|c|}
\hline Variable & Sensitivity & Specificity & $\begin{array}{c}+ \text { +ve } \\
\text { predictive }\end{array}$ & $\begin{array}{c}\text {-ve } \\
\text { predictive }\end{array}$ & Accuracy \\
\hline US & $63.6 \%$ & $100 \%$ & $63.6 \%$ & $77.8 \%$ & $81.8 \%$ \\
\hline MRI & $90.9 \%$ & $85.7 \%$ & $90.9 \%$ & $85.7 \%$ & $88.3 \%$ \\
\hline
\end{tabular}

\section{DISCUSSION}

Women with placenta previa and one cesarian delivery have been found to have $24 \%$ chance of placenta accreta. Their risk increases to as high as $67 \%$ with four previous cesarians and placenta previa. Therefore the surgical history of a patient is extremely valuable in identifying women at highest risk for accreta. (Burton,et al, 2017)

Ultrasound is virtually always the first imaging modality used to evaluate suspected placenta accreta. This modality has enjoyed great popularity because it is widely available, patient friendly, and relatively inexpensive.(Riteau,et al 2014)

However, some authors have pointed out that US might be limited in the extent to which it can assess depth of invasion in women with suspected placenta accreta. Others asserted that US lacks the necessary resolution to identify accreta in posterior placenta or the patient's body habitus presents a barrier through the scan. (Burton,et al, 2017)
MRI has been suggested as an alternative to US. It theoretically offers the advantage of greater soft tissue contrast, thereby providing enhanced resolution and allowing accurate measurement of depth of invasion. It has shown to be beneficial in some cases when ultrasound findings are equivocal or nondiagnostic. (Riteau,et al 2014)

The specificity of the US and MRI was higher in our study which may be due to the fact that on US basis we had made use of transvaginal sonography.

Concerning MRI we had performed spin echo sequences with controlled breath hold, such an option had provided images of better resolution and almost nil motion artifacts from fetal body motion and maternal bowel peristalsis and respiration.

The strength of our study was that: (1) it had evaluated the individual ability of MR imaging and Ultrasound to predict placenta accreta in the same group of cases, (2) 
sensitivity and specificity of MR were estimated without the use of gadolinium.

\section{CONCLUSION}

Ultrasonography (US) is the main imaging modality and the primary investigation, it has $100 \%$ specificity and can be used as a good negative test.

MRI is a complementery technique used for better tissue characterization when ultrasound is not conclusive or equivocal as it is more sensitive.

\section{ABBREVIATIONS}

CS : Caeserian Section.

FOV : Field Of View..

MRI : Magnetic Resonance Imaging.

PA : Placenta Accreta.

US : Ultrasound.

\section{ACKNOWLEDGEMENTS}

I would like to express my deepest gratitude and appreciation to Ass.Prof. Dr. Ashraf Talaat Youssef, Assistant Professor of Radiology, Faculty of Medicine, Fayoum University \& Dr. Abdullah Abbass Abdulfattah, Lecturer of Radiology,
Faculty of $\mathrm{M}$ edicine, Fayoum University, for their continuous support and kind help.

It is my pleasure to express my deep appreciation to my professors and colleagues in the Radiology as well as Obstetrics \& Gynecology departments, Fayoum University.

\section{REFERENCES}

1. Burton, Graham J., Amar Bhide, and Eric Jauniaux. "Pathophysiology of Accreta." Placenta Accreta Syndrome. CRC Press, 2017. 23-38.

2. Magied, Asmaa M. Abdel, et al. "Placenta previa; MRI as an adjunct to ultrasound in assessment of suspected placental invasion." The Egyptian Journal of Radiology and Nuclear Medicine 49.1 (2018): 284-291.

3. Mansour SM and Elkhayat WM. Placenta previa - accreta: Do we need MR imaging? The Egyptian Journal of Radiology and Nuclear Medicine , 2011; 42:433-442

4. Riteau, Anne-Sophie, et al. "Accuracy of ultrasonography and magnetic resonance imaging in the diagnosis of placenta accreta." PLoS One 9.4 (2014): e94866.

5. Silver, Robert M., et al. "Center of excellence for placenta accreta." American journal of obstetrics and gynecology 212.5 (2015): 561-568. 